${ }^{9}$ Serjeant, G R, Serjeant, B, and Mason, K, Lancet, 1977, 1, 795.

${ }^{10}$ Hegyi, T, et al, Pediatrics, 1977, 60, 213

${ }^{11}$ Porter, F S, and Thurman, W G, American fournal of Diseases of Children, 1963, 106, 35.

1.2 Watson, R J, et al, Pediatrics, 1963, 31, 975.

13. Seeler, R A, Clinical Pediatrics, 1972, 11, 634.

${ }^{14}$ Robinson, M G, and Watson, R J, New England fournal of Medicine, 1966, 274, 1006.

15 Singer, K, Motulsky, A G, and Wile, S A, fournal of Laboratory and Clinical Medicine, 1950, 35, 721

${ }^{16}$ Seeler, R A, and Schwiaki, M Z, Clinical Pediatrics, 1972, 11, 701.

17 Jenkins, M E, Scott, R B, and Baird, R L, fournal of Pediatrics, 1960, $56,30$.

1s Mann, J R, et al, fournal of Clinical Pathology, 1975, 28, 341

19 MacIver, J E, and Went, L N, British Medical fournal, 1960, 1, 775.

21) Barrett-Connor, E, fournal of the American Medical Association, 1973, 224, 997.

${ }^{21}$ Evans, D I K, and Blair, V M, Archives of Disease in Childhood, 1976, 51, 127.

\section{Social class, occupation, life, and death}

Mid-nineteenth century Britain abounded with people whose ingenuity opened new knowledge; it seemed that a man who could combine industry, ingenuity, and confidence was almost guaranteed world prominence. Somehow in many subjects the confidence, and with it the top-ranking, have been lost. A striking exception is health statistics, and, while the latest decennial supplement of the Registrar General ${ }^{1}$ on occupational mortality is the 12 th of a series, it is in many ways a pioneer document.

William Farr-a typical great Victorian-developed a workable system not only for collecting reliable national data on births, marriages, and deaths but also for analysing and interpreting them. Among his many interests Farr studied the inequitable distribution of mortality: the poor died young, and the rich survived. Apart from identifying diseases to which particular occupations were prone, his approach to comparing mortality patterns among sections of the population was by area or residence-in effect an attempt to classify persons by the place they lived in. It was this approach that led him to subscribe to the miasma theory of the aetiology of cholera (because those who died had resided on the low ground near the Thames) and so to make one of his few errors. Meanwhile John Snow ${ }^{2}$ had considered place and person separately and was able to conclude over a decade before Pasteur's work bore fruit "that the quantity of morbid matter which is sufficient to produce cholera is inconceivably small ... having the property of reproducing its own kind, must necessarily have some sort of structure, most likely that of a cell."

As this latest supplement indicates in a historical introductory section, it was $\mathrm{T} \mathrm{H} \mathrm{C} \mathrm{Stevenson,}{ }^{3}$ a successor to Farr, who first separated the poor from the rich in mortality statistics. He aggregated occupations according to their status in the rigidly stratified society of Edwardian Britain. This fundamental statistical solution to a problem was reached long before sociology had emerged as a science. By combining information about occupation and marital status from death certificates with similar information collected in the decennial censuses it became possible to treat characteristics of place and person separately in the study of mortality.

The 12th supplement takes several more steps forward. The original system of social classification has become less valid for many reasons - in particular, more people are continuing their education beyond the minimum and more women are working throughout their married lives. The supplement gives separate analyses of mortality from principal causes in married women according to their own and their husband's occupation for the first time. These show differences; for instance, there is an excess of deaths from accidents, poisonings, and violence in $\stackrel{\varrho}{c}$

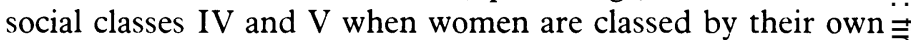
occupation which is not evident when they are classified by $\stackrel{5}{+}$ their husband's, and there are striking but more complex differences between the two groups in deaths from mental $\frac{0}{\bar{c}}$ disorders. Other innovations include a lucid commentary on $\overrightarrow{\mathbb{D}}$ the social class characteristics of deaths in childhood and an $\cong$ attempt to disentangle those risk factors underlying fatal ${ }^{\infty}$ diseases which can be associated with occupation per se from $\vec{\circ}$ those which are related to other aspects of social status.

The picture of the health of the nation that emerges is $\mathscr{\omega}$ depressing. Living standards have risen: of the households of $\frac{\text { 을 }}{3}$ unskilled manual workers (the lowest of the seven social classes considered in the General Household Survey), $18^{\circ}{ }_{0}$ o owned a car, $19^{\circ}$, had central heating, $60 \%$, a washing machine; N only $1 \%$ had no water closet. These figures were unthinkable $\vec{A}$ 20 years ago. Yet, improvements in living standards notwith- $t$ standing, for every major cause of death the standardised mortality ratios (SMRs) are higher and usually far higher in $\omega$ social class $\mathrm{V}$ than in any other social class (with the exception of cancer of the breast and mental disorders in women and $\vec{\Phi}$ diseases of the blood and blood-forming organs in men). For $\overrightarrow{0}$ respiratory disease SMRs in each sex are nearly twice the $\infty$ national average in class V, and less than half of it in class I.

In common with the earlier ones in the series, these analyses make extensive use of the SMR. Like the proportional mortality ratio (PMR), which is used for ages over 65 years, ٌ the SMR is a summary statistic with all the concomitant $\stackrel{\mathbb{Q}}{\mathbb{Q}}$ merits and demerits. For instance, the SMR for ischaemic $\overrightarrow{\vec{A}}$ heart disease in social class I was 237 in 1930-2 and 150 in 3 1949-53; it had fallen to 98 in 1959-63 and to 88 in 1970-2. The SMR cannot tell us that between 1951 and 1971 the crude mortality rates from ischaemic heart disease in all men almost doubled, rising from 1.8 to 3.5 per thousand. Nor do SMRs allow us to make direct comparisons of death rates between $\frac{0}{3}$ men and women in general within an occupation, or between occupations, all of which could be done if direct standardisation were used. This is all explained quite clearly in the Supplement. ${ }^{1}$ The direct procedure, like the indirect, does $\frac{\text { T }}{5}$ have its disadvantages, but it would be interesting to see some $\mathbb{N}$ experiments made with its use. Perhaps we can look forward $\frac{D}{0}$ to this next time; meanwhile it is good to know that reports of occupational mortality based on sampling procedures will $N$ be made available annually.

Despite all the innovations the volume is thinner and? lighter than its predecessor, thanks in part to the use of new printing techniques and in part to another innovation, the preparation of many tables on microfiches which are obtainable on request. At $£ 4.75$ the price is 15 pence cheaper, yet it took $\dot{O}^{\circ}$ four years less to produce than the previous decennial $\stackrel{\mathbb{\Phi}}{\circ}$ supplement, which was published in 1971. It is something to $\stackrel{\mathbb{Q}}{\stackrel{\mathbb{Q}}{\Omega}}$ be proud of.

${ }^{1}$ Office of Population Censuses and Surveys, Occupational Mortality. Decennial Supplement England and Wales 1970-1972. London, HMSO, 1978.

2 Snow, J, On the mode of communication of cholera, 1855, in Snow on Cholera, pp 15 and 54. New York, Hafner, 1965.

${ }^{3}$ Stevenson, T H C, Biometrika, 1923, 15, 382. 